\title{
The brief scale for anxiety: a subdivision of the comprehensive psychopathological rating scale
}

\author{
P TYRER, RT OWEN, DV CICCHETTI \\ From the Mapperley Hospital, Nottingham, UK and Veterans Administration Medical Center, West Haven, \\ Connecticut, USA
}

SUMMARY A rating scale suitable for recording anxious symptoms is described. It is a subdivision of the Comprehensive Psychopathological Rating Scale and comprises 10 items, all of which are rated on a 7 point scale. It is suitable for the rating of pathological anxiety alone or for anxiety occurring in the setting of other psychological or medical disorder.

The rating of anxiety is a long-established psychometric exercise and there are more than 20 instruments available. It is important to recognise that anxiety is variously described as a normal emotion, a pathological mood state and a personality characteristic. The rating scales for these are not interchangeable and both loose nomenclature and indiscriminate use have aroused confusion in the past.' $A$ distinction must also be made between self rating scales completed by the subject and observer scales rated by a trained assessor.

The most commonly used observer scale for anxiety as a pathological mood state is the Hamilton Rating Scale for Anxiety. ${ }^{2}$ It is used internationally and has proved sturdy and reliable in over 20 years of use. However, Hamilton did not consider the scale to be in its final state and Snaith and his colleagues have modified the scale which now only contains six items. ${ }^{3}$ Other observer scales for anxiety include the Buss Rating $\mathrm{Scale}^{4}$ and the Anxiety Status Inventory ${ }^{5}$ but they have never achieved the popularity of the Hamilton Rating Scale for Anxiety.

The authors of these scales emphasise that they are not diagnostic instruments and should only be used in patients who are diagnosed as having anxiety states. However, in clinical practice anxiety is often mixed with other emotions and it is difficult, if not impossible, to separate the anxiety element. ${ }^{6}$ In research studies investigators often wish to know if pathological anxiety changes over time in a popula-

Address for reprint requests: Dr PJ Tyrer, Mapperley Hospital, Porchester Rd, Nottingham, NG3 6AA, UK

Received 24 January 1984. Accepted 10 March 1984 tion that does not have classical anxiety neurosis. Recording changes in other mood states, particularly depression, may also be required. The Comprehensive Psychopathological Rating Scale ${ }^{7}$ is an interview rating scale consisting of 65 items (40 symptoms and 25 observed items) that covers the range of psychopathology. Sub-scales have been derived from the original Scale for depression, schizophrenia ${ }^{9}$ and obsessional neurosis. ${ }^{10}$ These may be used independently or scored together with other items from the Comprehensive Psychopathological Rating Scale.

We thought it would be useful to have an anxiety sub-scale of the Comprehensive Psychopathological Rating Scale as this would allow assessment of anxious symptoms in other psychiatric patients apart from those with anxiety neurosis. It would be of particular value in assessing mixed states of anxiety with depressive, phobic, obsessional or psychotic symptoms, or in pathological anxiety occurring in medical and neurological disorders.

\section{Method}

We studied a series of anxious patients seen in general practice psychiatric clinics who had taken part in two studies of drug treatment. In both studies patients were included if they satisfied the diagnostic criteria for anxiety neurosis using the International Classification of Disease ${ }^{11}$ and either Panic Disorder, Generalised Anxiety Disorder or Agoraphobia with Panic Attacks using the American Psychiatric Classification, DSM-111. ${ }^{13}$ As a homogeneous sample of relatively "pure" anxious patients was needed only data from those with Panic Disorder and Generalised Anxiety Disorder were included in this study. Panic Disorder is not recognised as a diagnostic entity in Europe as patients with symptoms of panic are subsumed within anxi- 
ety neurosis, but it was felt appropriate to include Panic Disorder in this analysis as the symptoms of panic are those of severe anxiety.

In both studies patients had taken no drug treatment for at least two weeks before first assessment. In the first study each patient took buspirone, a new non-benzodiazepine anti-anxiety drug, diazepam, a standard benzodiazepine prescribed for anxiety, and placebo for one week each in a cross-over design with balanced drug order. ${ }^{13}$ The drugs were dispensed in capsules of identical appearance and administered in flexible dosage using a double-blind procedure. The Comprehensive Psychopathological Rating Scale was administered before treatment and after each week. The second study involved assessment of the effects of buspirone and diazepam over six weeks of therapy. A parallel design was used; patients were randomly allocated to buspirone or diazepam and took this drug throughout the six weeks. After this time the drugs were withdrawn at different times to evaluate the extent of withdrawal symptoms and only the first six-week data are analysed here.

The data were analysed to find (a) the most commonly scored items from the Comprehensive Psychopathological Rating Scale in the anxious patients, and (b) the items that were most sensitive to treatment, and (c) the extent of inter-correlation between the individual items found in anxiety. The Brief Scale for Anxiety was constructed from these three analyses so that all the items included were common in pathological anxiety, changed in response to treatment and were relatively independent of one another.

\section{Results}

Fifty patients were examined, all of whom had Generalised Anxiety Disorder or Panic Disorder. Thirty-three completed the first study and 13 were examined from the second study. Four patients were also seen who did not complete either study. The frequencies of each Comprehensive Psychopathological Rating Scale item were examined in all 50 patients as only the initial assessments were required. These are shown in table 1 in which both the mean scores and frequencies of scores above zero are shown. Only 14 items were scored in at least half the patients and most of these are immediately recognisable as anxious symptoms.

The sensitivity to change was measured by single group, repeated measures one-way analyses of variance of scores for each symptom score over time. The significant F-ratios for these analyses are shown in table 2. The four most frequent anxious symptom showed the most changes with treatment although fatiguability and diffiulty in concentration, despite occurring frequently in anxious patients, showed no significant change with treatment in either study. An intercorrelation matrix of the scores at initial assessments for the items showing significant change with treatment was constructed to determine if any of the anxious items were redundant because of high
Table 1 Mean scores and frequencies of scored items from the Comprehensive Psychopathological Rating Scale (CPRS) in 50 anxious patients

\begin{tabular}{lll}
\hline CPRS item & $\begin{array}{l}\text { Mean score } \\
(0-3)\end{array}$ & $\begin{array}{l}\text { Frequency of } \\
\text { scores above } \\
\text { zero (\%) }\end{array}$ \\
\hline Inner tension (symptom) & 1.64 & 94 \\
Autonomic disturbances (symptom) & 1.52 & 90 \\
Phobias (symptom) & 1.42 & 86 \\
Reduced sleep (symptom) & 1.16 & 70 \\
Muscular tension (observed) & 1.08 & 72 \\
Muscular tension (symptom) & 1.06 & 74 \\
Worrying over trifles (symptom) & 0.86 & 66 \\
Fatiguability (symptom) & 0.86 & 60 \\
Aches and pains (symptom) & 0.76 & 50 \\
Hostile feelings (symptom) & 0.70 & 54 \\
Reduced sexual interest (symptom) & 0.70 & 36 \\
Autonomic disturbances (observed) & 0.66 & 52 \\
Concentration difficulties (symptom) & 0.64 & 52 \\
Inability to feel (symptom) & 0.62 & 54 \\
Hypochondriasis (symptom) & 0.58 & 50 \\
Lassitude (symptom) & 0.48 & 38 \\
Reduced appetite (symptom) & 0.46 & 30 \\
Indecision (symptom) & 0.36 & 36 \\
Apparent sadness (observed) & 0.34 & 32 \\
Failing memory (symptom) & 0.34 & 28 \\
Agitation (observed) & 0.32 & 30 \\
\hline
\end{tabular}

Table 2 Sensitivity to change of items from the Comprehensive Psychopathological Rating Scale in anxious patients

\begin{tabular}{lll}
\hline CPRS item & \multicolumn{2}{l}{ Significance of $F$-ratios } \\
\cline { 2 - 3 } & $\begin{array}{l}\text { study } 1 \\
(n=33)\end{array}$ & $\begin{array}{l}\text { study } 2 \\
(n=13)\end{array}$ \\
\hline Inner tension (symptom) & $<0.001$ & $<0.001$ \\
Phobias (symptom) & $<0.001$ & $<0.001$ \\
Reduced sleep (symptom) & $<0.001$ & $<0.001$ \\
Autonomic disturbances (symptom) & $<0.001$ & $<0.05$ \\
Muscular tension (observed) & $<0.001$ & $<0.05$ \\
Reduced appetite (symptom) & $<0.05$ & $<0.05$ \\
Inability to feel (symptom) & $<0.05$ & $<0.05$ \\
Aches and pains (symptom) & $<0.001$ & NS \\
Hypochondriasis (symptom) & $<0.001$ & NS \\
Muscular tension (symptom) & $<0.001$ & NS \\
Autonomic disturbances (observed) & $<0.001$ & NS \\
Worying over trifles (symptom) & $<0.01$ & NS \\
Agitation (observed) & $<0.01$ & NS \\
Apparent sadness (observed) & NS & $<0.01$ \\
Hostile feelings (symptom) & NS & $<0.01$ \\
Suicidal thoughts (symptom) & $<0.05$ & NS \\
Indecision (symptom) & $<0.05$ & NS \\
Labile emotional responses & & \\
(observed) & $<0.05$ & NS \\
\hline
\end{tabular}

The F-ratios are those of analyses of variance between scores at different times in the studies. No other items showed change at the $5 \%$ level of significance.

correlation with other items. Only seven pairs of items were intercorrelated at the $1 \%$ level of significance or greater (table 3 ), and only one pair (muscular tension-symptom/muscular tensionobserved) was significant at the level of greater than $0 \cdot 1 \%$. As the matrix involved 312 comparisons at least two of these significant correlations could have occurred by chance.

The Brief Scale for Anxiety was constructed from the results of all three types of analysis. To justify 
Table 3 Significant intercorrelations between items from the Comprehensive Psychopathological Rating Scale in study 1 $(n=33)$ and study $2(n=13)$

\begin{tabular}{|c|c|c|c|}
\hline Correlated items & Study & $\begin{array}{l}\text { Correlation and } \\
\text { coefficient }\end{array}$ & Significance level \\
\hline $\begin{array}{l}\text { Muscular tension (observed) } \\
\text { Muscular tension (symptom) }\end{array}$ & 1 & 0.70 & 0.0001 \\
\hline $\begin{array}{l}\text { Phobias (symptom) } \\
\text { Inabiity to feel (symptom) }\end{array}$ & 2 & 0.76 & 0.002 \\
\hline $\begin{array}{l}\text { Inner tension (symptom) } \\
\text { Phobias (symptom) }\end{array}$ & 1 & 0.48 & 0.005 \\
\hline $\begin{array}{l}\text { Inner tension (symptom) } \\
\text { Autonomic disturbances (symptom) }\end{array}$ & 2 & 0.71 & 0.007 \\
\hline $\begin{array}{l}\text { Suicidal thoughts (symptom) } \\
\text { Reduced sleep (symptom) }\end{array}$ & 1 & 0.46 & 0.007 \\
\hline $\begin{array}{l}\text { Worrying over trifles (symptom) } \\
\text { Aches and pains (symptom) }\end{array}$ & 1 & 0.46 & $0 \cdot 007$ \\
\hline $\begin{array}{l}\text { Autonomic disturbances (symptom) } \\
\text { Reduced appetite (symptom) }\end{array}$ & 2 & 0.66 & 0.01 \\
\hline
\end{tabular}

No other intercorrelations achieved significance at the $1 \%$ level or greater.

inclusion items had to be scored in at least $50 \%$ of patients, to show significant change with treatment at the $1 \%$ level of significance or greater in at least one study, and to be intercorrelated with other included items at the $0.1 \%$ level of significance or less. Of the 14 items scored in $50 \%$ of the patients or more, three (fatiguability, inability to feel and concentration difficulties) were excluded on grounds of insensitivity to change and one (muscular tension-symptom) because of its high intercorrelation with muscular tension-observed. The 10 items constituting the scale are shown in the appendix using a similar 7 point scale to that of Montgomery and Åsberg. ${ }^{8}$

\section{Discussion}

The Brief Scale for Anxiety shows some overlap with the items included in the Depression and Obsessional Scale derived from the Comprehensive Psychopathological Rating Scale but this reflects the difficulties in separating anxiety from other mood states in clinical practice. The items of the scale cover all the important anxious symptoms and although many other symptoms such as depersonalisation and derealisation may be found in anxiety ${ }^{14}$ they do not occur with sufficient frequency in uncomplicated anxiety states to justify inclusion. The item of hostile feelings may appear a little unusual in the scale but is interpreted as irritability by many raters, and this is a common symptom in anxiety. This item shows some cross-national differences in rating as it is less frequently rated by Swedish patients. ${ }^{15}$ There may also be subtle differences in interpretation of the item following translation into English.

The scale may be used as part of the Comprehensive Psychopathological Rating Scale or alone, although if the population being tested has considerable psychopathology it would be better to use the full Comprehensive Psychopathological Rating Scale and score the anxiety sub-scale separately. If the Brief Scale for Anxiety alone is used it takes about 10-15 minutes to complete and can readily be used to record changes in symptoms at intervals of 1 week or more.

Although the Comprehensive Psychopathological Rating Scale is carried out with only four scored points for each item when using the Brief Scale for $\propto$ Anxiety alone it is preferable to use the seven point scale. Increasing the number of points in a scale has no adverse impact on reliability ${ }^{16}$ and a recently completed, as yet unpublished study by two of the authors (DVC, PT and colleagues) has shown that seven points in a scale achieves the an optimal level of reliability assuming equivalence of other factors. ${ }^{17}$

The Brief Scale for Anxiety also illustrates the separation between somatic and psychological component of anxiety, both of which are present together in classical anxiety states. Four items (inner tension, hostile feelings, worrying over trifles and phobias) are psychological symptoms of anxiety and five (hypochondriasis, autonomic disturbancessymptoms and observed, aches and pains and muscular tension) are clear-cut somatic anxious symptoms. Reduced sleep is best considered independently. If there is particular interest in differentiating between the effects of psychological and somatic symptoms of anxiety the scores for the psychological and somatic components can be analysed separately. There may also be merits in scoring the two observed items (muscle tension and autonomic disturbances) separately from the other items which are all symptoms.

We thank Linda Humphreys and Marlene Whitaker for secretarial help and Lorraine Gambino for assis- 
tance in carrying out the analyses. We are also grateful to Professor Marie Åsberg and Dr. Stuart Montgomery for advice, encouragement and criticism.

\section{References}

' Taylor-Spence J. What can you say about a twentyyear-old theory that won't die. J Motor Behav 1971;3:193-203.

${ }^{2}$ Hamilton $M$. The assessment of anxiety states by rating. Br J Med Psychol 1959;32:50-5.

${ }^{3}$ Snaith RP, Baugh SJ, Clayden AD, Husain A, Sipple MA. The Clinical Anxiety Scale: an instrument derived from the Hamilton Anxiety Scale. $\mathrm{Br} J$ Psychiatry 1982;141:518-23.

${ }^{4}$ Buss AH, Wiener M, Durkee A, Baer M. The measurement of anxiety in clinical situations. $J$ Consult Psychol 1955;19:125-9

s Zung WWK. A rating instrument for anxiety disorders. Psychosom 1971;12:371-9.

- Tyrer P. Classification of anxiety. Br J Psychiatry 1984; 144:78-83.

' Åsberg M, Montgomery SA, Perris C, Schalling D, Sedvall G. A comprehensive psychopathological rating scale. Acta Psychiat Scand 1978;Suppl 271:5-29.

${ }^{8}$ Montgomery SA, Åsberg M. A new depression scale designed to be sensitive to change. $\mathrm{Br} J$ Psychiatry 1979;134:382-9.
${ }^{9}$ Montgomery SA, Taylor R, Montgomery DB Development of a schizophrenia scale sensitive to change. Neuropharmacol 1978;17:1061-3.

${ }^{10}$ Montgomery SA, Montgomery DB. Measurement of change in psychiatric illness: new obsessional, schizophrenia and depression scales. Postgrad Med J 1980;56(Suppl 1):50-2.

1 World Health Organisation. International Classification of Disease, 9th Revision. Geneva: W.H.O., 1978.

${ }^{12}$ American Psychiatric Association. Diagnostic and Statistical Manual of Mental Disorders, 3rd Edition. Washington: A.P.A., 1980.

${ }^{13}$ Tyrer $\mathrm{P}$, Owen $\mathrm{R}$. Treatment of anxiety in primary care: is short-term drug treatment appropriate? J Psychiat Res 1984;18:73-8.

${ }^{14}$ Roth M, Gurney C, Garside RF, Kerr TA. Studies in the classification of affective disorders: the relationship between anxiety states and depressive illnesses-1. $\mathrm{Br}$ J Psychiatry 1972;121:147-61.

15 Åsberg M, Schalling D. Construction of a new psychiatric rating instrument, the Comprehensive Psychypathological Rating Scale. Neuropsychopharmacology, Proceedings of the XII Congress of the Collegium Internationale Neuropsychopharmacologicum. Amsterdam: Excerpta Medica.

${ }^{16}$ Remington M, Tyrer PJ, Newson-Smith J, Cicchetti DV. Comparative reliability of categorical and analogue rating scales in the assessment of psychiatric symptomatology. Psychol Med 1979;9:765-70. 


\section{Appendix}

\section{BRIEF ANXIETY SCALE}

Instructions

The ratings should be based on a clinical interview. At first the subject is asked to describe symptoms using his own words and this is followed by detailed questions to determine the severity of symptoms for each item. The rater must decide whether the rating lies on the defined scale steps $(0,2,4,6)$ or in between them $(1,3,5)$. If other symptoms apart from anxiety are present the rating scale can still be used but only the anxiety items are scored.

\section{Inner tension}

Representing feelings of ill-defined discomfort, edginess, inner turmoil, mental tension mounting to panic, dread and anguish. Rate according to intensity, frequency, duration and the extent of reassurance called for.

\begin{tabular}{llllll}
\hline 0 & 1 & 2 & 4 & 5 \\
$\begin{array}{l}\text { Placid. Only fleeting } \\
\text { inner tension }\end{array}$ & $\begin{array}{l}\text { Occasional feelings of } \\
\text { edginess and ill } \\
\text { defined discomfort }\end{array}$ & $\begin{array}{l}\text { Continuous feelings of } \\
\text { inner tension, or } \\
\text { intermittent which the } \\
\text { patient can only } \\
\text { master with some } \\
\text { difficulty }\end{array}$ & $\begin{array}{l}\text { Unrelenting dread or } \\
\text { anguish }\end{array}$ & \\
& & &
\end{tabular}

\section{Hostile feelings}

Representing anger, hostility and aggressive feelings regardless of whether they are acted or not. Rate according to intensity, frequency and the amount of provocation tolerated.

\begin{tabular}{llllll}
\hline 0 & 1 & 2 & 3 & 4 & 5 \\
Not easily angered & $\begin{array}{l}\text { Easily angered. Reports } \\
\text { hostile feelings which are } \\
\text { easily dissipated }\end{array}$ & $\begin{array}{l}\text { Reacts to provocation with } \\
\text { excessive anger and } \\
\text { hostility }\end{array}$ & $\begin{array}{l}6 \\
\text { Persistent anger, rage or } \\
\text { intense hatred which } \\
\text { difficult or impossible to } \\
\text { control }\end{array}$
\end{tabular}

\section{Hypochondriasis}

Representing exaggerated preoccupation or unrealistic worrying about ill health or disease. Distinguish from worrying over trifles and aches and pains.

\begin{tabular}{|c|c|c|c|c|c|c|}
\hline $\begin{array}{l}0 \\
\text { No particular } \\
\text { preoccupation with } \\
\text { ill health }\end{array}$ & 1 & $\begin{array}{l}2 \\
\text { Reacting to minor bodily } \\
\text { dysfunction with fore- } \\
\text { boding. Exaggerated fear } \\
\text { of disease }\end{array}$ & 3 & $\begin{array}{l}4 \\
\text { Convinced that there is } \\
\text { some disease but can be } \\
\text { reassured, if only briefly }\end{array}$ & 5 & $\begin{array}{l}6 \\
\text { Incapacitating or absurd } \\
\text { hypochondriacal convic- } \\
\text { tions (body rotting away, } \\
\text { bowels have not worked } \\
\text { for months) }\end{array}$ \\
\hline
\end{tabular}

4. Worrying over trifles

Representing apprehension, and undue concern trifles, which is difficult to stop and out of proportion to the circumstances.

\begin{tabular}{|c|c|c|c|c|c|c|}
\hline $\begin{array}{l}0 \\
\text { No particular } \\
\text { worries }\end{array}$ & 1 & $\begin{array}{l}2 \\
\text { Undue concern, worrying } \\
\text { that can be shaken off }\end{array}$ & 3 & $\begin{array}{l}4 \\
\text { Apprehensive and } \\
\text { bothered about trifles or } \\
\text { minor daily routines }\end{array}$ & 5 & $\begin{array}{l}6 \\
\text { Unrelenting and often } \\
\text { painful worrying. } \\
\text { Reassurance is ineffective }\end{array}$ \\
\hline
\end{tabular}

\section{Phobias}

Representing feelings of unreasonable fear in specific situations (such as buses, supermarkets, crowds, feeling enclosed, being alone) which are avoided if possible.

\begin{tabular}{|c|c|c|c|c|c|c|}
\hline $\begin{array}{l}0 \\
\text { No phobias }\end{array}$ & 1 & $\begin{array}{l}2 \\
\text { Feelings of vague } \\
\text { discomfort in particular } \\
\text { situations which can be } \\
\text { mastered without help or } \\
\text { by taking simple } \\
\text { precautions like avoiding }\end{array}$ & 3 & $\begin{array}{l}4 \\
\text { Certain situations } \\
\text { consistently provoked } \\
\text { marked discomfort, and } \\
\text { are avoided without } \\
\text { impairing social } \\
\text { performance }\end{array}$ & 5 & $\begin{array}{l}6 \\
\text { Incapacitating phobias } \\
\text { which severely restrict } \\
\text { activities, for example } \\
\text { completely unable to leave } \\
\text { home }\end{array}$ \\
\hline
\end{tabular}


6. Reduced sleep

Representing a subjective experience of reduced duration or depth of sleep compared to the subject's own normal pattern when well.

\begin{tabular}{lllllll}
\hline $\begin{array}{l}\text { Sleeps as usual } \\
\text { S }\end{array}$ & 1 & $\begin{array}{l}2 \\
\text { Slight difficulty dropping } \\
\text { off to sleep or slightly } \\
\text { reduced, light or fitful sleep }\end{array}$ & $\begin{array}{l}4 \\
\text { Sleep reduced or broken } \\
\text { by at least 2 hours }\end{array}$ & $\begin{array}{l}5 \\
\text { Less than two or three } \\
\text { hours' sleep }\end{array}$
\end{tabular}

\section{Autonomic disturbances}

Representing descriptions of palpitations, breathing difficulties, dizziness, increased sweating, cold hands and feet, dry mouth, indigestion, diarrhoea, frequent micturition. Distinguish from inner tension and aches and pains.

\begin{tabular}{lllllll}
\hline 0 & 1 & 2 & 3 & 4 & 5 \\
$\begin{array}{l}\text { No autonomic } \\
\text { disturbances }\end{array}$ & $\begin{array}{l}\text { Occasional autonomic } \\
\text { symptoms which occur } \\
\text { under emotional stress }\end{array}$ & $\begin{array}{l}\text { Frequent or intense } \\
\text { autonomic disturbances } \\
\text { which are experienced as } \\
\text { discomforting or socially } \\
\text { inconvenient }\end{array}$ & $\begin{array}{l}\text { Very frequent autonomic } \\
\text { disturbances which } \\
\text { interrupt other activities } \\
\text { or are incapacitating }\end{array}$ \\
\hline
\end{tabular}

\section{Aches and pains}

Representing reports of bodily discomfort, aches and pains. Rate according to intensity, frequency and duration, and also request for relief. Disregard any symptom of organic cause. Distinguish from hypochondriasis, autonomic disturbance, and muscular tension.

\begin{tabular}{llllll}
\hline $\begin{array}{l}\text { Absent or transient } \\
\text { aches }\end{array}$ & $\begin{array}{l}2 \\
\text { Occasional definite aches } \\
\text { and pains }\end{array}$ & $\begin{array}{l}\text { and } \\
\text { Prolonged and } \\
\text { inconvenient aches and } \\
\text { pains. Requests for }\end{array}$ & $\begin{array}{l}6 \\
\text { Severely interfering or } \\
\text { crippling pains }\end{array}$
\end{tabular}

\section{Autonomic disturbances}

Representing signs of autonomic dysfunction, hyperventilation or frequent sighing, blushing, sweating, cold hands, enlarged pupils and dry mouth, fainting.

\begin{tabular}{llllll}
\hline 0 & 1 & 2 & 3 & 4 & 5 \\
$\begin{array}{l}\text { No observed } \\
\text { autonomic } \\
\text { disturbances }\end{array}$ & $\begin{array}{l}\text { Occasional or slight } \\
\text { autonomic disturbances } \\
\text { such as blushing or } \\
\text { blanching, or sweating } \\
\text { under stress }\end{array}$ & $\begin{array}{l}\text { Obvious autonomic } \\
\text { disturbance on several } \\
\text { occasions even when not } \\
\text { under stress }\end{array}$ & $\begin{array}{l}\text { Autonomic disturbances } \\
\text { which disrupt the interview }\end{array}$ & \\
& & &
\end{tabular}

10. Muscular tension

Representing observed muscular tension as shown in facial expression, posture, and movements.

\begin{tabular}{llllll}
\hline 0 & 1 & 2 & 3 & 4 & 5
\end{tabular}

